УДК 616-002.71

\title{
К.Е.Гаврилов ${ }^{1}$, Е.В.Серебрякова ${ }^{1}$, Т.Ю.Дуняшева ${ }^{1}$, Н.Н.Зайцева ${ }^{1}$, Ю.Д.Еременко ${ }^{1}$, В.С.Лобастов ${ }^{1}$, А.А.Бывалов ${ }^{2}$ С.Л.Кузнецов ${ }^{3}$, И.В.Борисевич ${ }^{1}$ \\ БИОЛОГИЧЕСКИЕ И ФИЗИКО-ХИМИЧЕСКИЕ СВОЙСТВА КУЛЬТУР YERSINIA PSEUDOTUBERCULOSIS В ДИНАМИКЕ ГЛУБИННОГО ВЫРАЩИВАНИЯ ПРИ РАЗЛИЧНЫХ ТЕМПЕРАТУРАХ
}

\begin{abstract}
${ }^{I}$ Федеральное государственное учреждение «48 Центральный научно-исследовательский институт

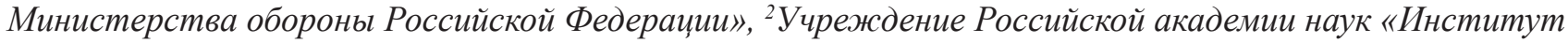

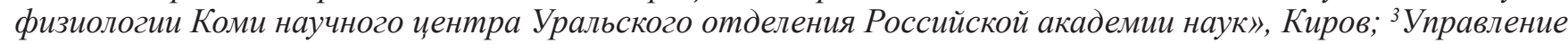
биологической защиты Управления начальника войск радиачионной, химической и биологической защиты Вооруженных Сил Российской Федерации, Москва
\end{abstract}

При изучении псевдотуберкулезного микроба при разных температурах выявлены различия в биологических и физико-химических свойствах культур в динамике глубинного выращивания. Установлено, что культивирование микроба при повышенной температуре $\left(37^{\circ} \mathrm{C}\right)$ характеризуется быстрым развитием популяции и быстрым ее отмиранием. В условиях низкой температуры характерны замедленная лаг-фаза, растянутая фаза экспоненциального роста. $27^{\circ} \mathrm{C}$-ная культура занимает промежуточное положение между $10{ }^{\circ} \mathrm{C}$ - и $37^{\circ} \mathrm{C}$-ными культурами.

Ключевые слова: Yersinia pseudotuberculosis, температура культивирования, липополисахарид.

Приспособительная активность микроорганизмов лежит в основе их изменчивости. Во многом эта способность определяет пластичность и слаженность обменных процессов, сложившихся в ходе эволюции конкретного вида. Характерной особенностью псевдотуберкулезного микроба как факультативного паразита является способность обитать вне макроорганизма в естественных биогеоценозах.

Исследования физиологии псевдотуберкулезного микроба носят весьма ограниченный характер. В лабораторных условиях имеется возможность работать на уровне относительно простой динамичной системы, в которой можно контролировать влияние условий культивирования на свойства микробных популяций. Представлялось, в частности, интересным оценить влияние температуры глубинного выращивания на функциональное состояние культур псевдотуберкулезного микроба от $10{ }^{\circ} \mathrm{C}$ (температура окружающей среды) до $37^{\circ} \mathrm{C}$ (температуры тела теплокровных хозяев возбудителя).

Целью работы являлось сравнительное изучение влияния температуры культивирования на биологические и физико-химические свойства культур в динамике глубинного выращивания Yersinia pseudotuberculosis.

\section{Материалы и методы}

В работе использовали спонтанный мутант штамма 164/84 $\quad$ Y.pseudotuberculosis, утративший плазмиду кальцийзависимости [6]. Культуру Y. pseudotuberculosis выращивали в ферментере АК-210 в жидкой питательной среде на основе ферментативного гидролизата мяса с содержанием $\mathrm{N}_{\mathrm{am}}=160 \mathrm{мг} \%$ (pH 6,9-7,2) при температуре 10,27 и $37^{\circ} \mathrm{C}$ в течение
120,30 и 36 ч соответственно, при непрерывной аэрации $(0,2-0,3$ объема воздуха на объем культуры в минуту) и механическом перемешивании (280 об'мин $\left.{ }^{-1}\right)$. Посевная доза составляла $0,5 \cdot 10^{9}$ м.к. в 1 мл питательной среды. Титр липополисахарида (ЛПС) в микробной суспензии оценивали в реакции непрямой гемагглютинации (РНГА) с эритроцитарным иммуноглобулиновым диагностикумом на основе поликлональных антител к ЛПС Y. pseudotuberculosis лабораторного производства. С этой целью отобранные пробы культуральной жидкости центрифугировали (15 мин при $4000 \mathrm{~g})$, осадок клеток разводили $0,9 \%$ раствором натрия хлорида до исходного объема и использовали для постановки РНГА. Определение оптической (ОК) и биологической концентраций (БК) проводили по общепринятым методикам. Процент живых клеток определяли по формуле:

$$
\% \text { живых кл. }=\frac{\text { БК }}{\mathrm{OK}} \cdot 100 \%
$$

Характеристику дыхания глубинных культур псевдотуберкулезного микроба осуществляли по ряду показателей:

- удельная эндогенная скорость потребления кислорода $\left(\mathrm{V}_{\text {уд.энд }}\right)$ определялась по формуле:

$$
\mathrm{V}_{\text {уд.энд. }}=\frac{\mathrm{V}_{\text {уд.энд }} \cdot \mathrm{V}_{\text {пр }}}{\mathrm{БK} \cdot \mathrm{V}_{\text {яч. }}}
$$

где $\mathrm{V}_{\text {энд. }}$ - удельная эндогенная скорость дыхания, в нмоль $\mathrm{O}_{2} \cdot$ млрд кл $^{-1}$ мин $^{-1} ; \mathrm{V}_{\text {пр. }}$ - объем пробы, мл; БК - биологическая концентрация, млрд кл. мл ${ }^{-1} ; \mathrm{V}_{\text {яч. }}-$ объем ячейки, мл;

- коэффициент стимуляции дыхания при окислении микробами экзогенной глюкозы (КСД ственно характеризующий уровень энергизованности и способности клеток ее изменять при аккумуляции 
Динамика концентрации микробов Y. pseudotuberculosis и накопления ЛПС в культуральной жидкости при глубинном выращивании при разных температурах $(\mathbf{n}=4)$

\begin{tabular}{|c|c|c|c|c|c|c|c|c|c|c|c|}
\hline \multirow{2}{*}{$\begin{array}{c}\text { Темпе- } \\
\text { ратура } \\
\text { выращи- } \\
\text { вания } \\
\text { культур, } \\
{ }^{\circ} \mathrm{C}\end{array}$} & \multirow[b]{2}{*}{$\begin{array}{c}\text { Показатель, } \\
\text { единица измерения }\end{array}$} & \multicolumn{10}{|c|}{ Значение показателя на . . . час культивирования } \\
\hline & & 0 & 12 & 18 & 24 & 30 & 36 & 48 & 72 & 96 & 120 \\
\hline \multirow[t]{3}{*}{10} & $\begin{array}{l}\text { Содержание ЛПС } \\
\text { в КЖ, АЕ }\end{array}$ & $8 \ldots 32$ & $32 \ldots 128$ & $64 \ldots 128$ & $128 \ldots .512$ & $256 \ldots 1024$ & $512 \ldots 2048$ & $1024 \ldots 2048$ & $2048 \ldots 4096$ & $2048 \ldots 4096$ & 2048 \\
\hline & $\begin{array}{l}\text { Концентрация } \\
\text { микробов (ОК), } \\
\mathrm{X} \pm \mathrm{I}_{95}, \text { млрд м.К. } \text { мл }^{-1}\end{array}$ & $5,3 \pm 2,6$ & $8,3 \pm 2,5$ & $9,1 \pm 2,8$ & $11,6 \pm 2,2$ & $15,6 \pm 1,3$ & $17,6 \pm 4,1$ & $23,6 \pm 4,1$ & $27,5 \pm 6,1$ & $32,7 \pm 7,9$ & $35,6 \pm 5,4$ \\
\hline & $\begin{array}{l}\text { Количество живых } \\
\text { микробов, } \% \pm_{95}\end{array}$ & $29,2 \pm 6,7$ & $27,1 \pm 7,5$ & $32,1 \pm 7,6$ & $29,3 \pm 4,8$ & $33,1 \pm 6,8$ & $30,1 \pm 6,2$ & $30,4 \pm 9,6$ & $33,2 \pm 6,5$ & $36,2 \pm 9,4$ & $32,4 \pm 4,8$ \\
\hline \multirow[t]{3}{*}{27} & $\begin{array}{l}\text { Содержание ЛПС } \\
\text { в КЖ, АЕ }\end{array}$ & $8 \ldots 32$ & $32 \ldots 128$ & $128 \ldots .256$ & $512 \ldots 2048$ & $1024 \ldots 2048$ & 2048 & - & - & - & - \\
\hline & $\begin{array}{l}\text { Концентрация } \\
\text { микробов (ОК), } \\
\mathrm{X} \pm \mathrm{I} 95, \text { млрд м.к. } \text { мл }^{-1}\end{array}$ & $4,2 \pm 1,2$ & $30,2 \pm 6,3$ & $40,1 \pm 7,3$ & $40,4 \pm 8,2$ & $65,3 \pm 8,8$ & $66,3 \pm 9,4$ & - & - & - & - \\
\hline & $\begin{array}{l}\text { Количество живых } \\
\text { микробов, } \% \pm \mathrm{I}_{95}\end{array}$ & $25,2 \pm 6,4$ & $32,5 \pm 7,1$ & $43,3 \pm 8,3$ & $40,2 \pm 7,9$ & $30,4 \pm 6,3$ & $66,3 \pm 9,4$ & - & - & - & - \\
\hline \multirow[t]{3}{*}{37} & $\begin{array}{l}\text { Содержание ЛПС } \\
\text { в КЖ, АЕ }\end{array}$ & $8 \ldots 64$ & $32 \ldots 128$ & $128 \ldots 512$ & $256 . .1024$ & $512 \ldots 2048$ & $512 \ldots 4096$ & $2048 \ldots 8192$ & - & - & - \\
\hline & $\begin{array}{l}\text { Концентрация } \\
\text { микробов (ОК), } \\
\mathrm{X} \pm \mathrm{I}_{95}, \text { млрд м.к. м. }{ }^{-1}\end{array}$ & $5,4 \pm 1,4$ & $13,6 \pm 4,8$ & $26,1 \pm 5,4$ & $31,4 \pm 3,9$ & $38,1 \pm 7,1$ & $44,2 \pm 8,5$ & $53,3 \pm 9,7$ & - & - & - \\
\hline & $\begin{array}{l}\text { Количество живых } \\
\text { микробов, \% } \text { I }_{95}\end{array}$ & $25,2 \pm 7,7$ & $28,9 \pm 12,0$ & $25,7 \pm 12,2$ & $17,9 \pm 5,8$ & $14,2 \pm 2,7$ & $11,52 \pm 1,3$ & $2,7 \pm 0,9$ & - & - & - \\
\hline
\end{tabular}

Примечания: АЕ - величина, обратная титрам, антигена, по данным РНГА, «-» - исследование не проводилось.

субстрата. КСД рости дыхания клеток после добавления в ячейку глюкозы $\left(\mathrm{V}_{\text {гл. }}\right)$ к предшествующей этой добавке эндогенной скорости дыхания $\left(\mathrm{V}_{\text {энд. }}\right)$ [5].

Природу клеточной поверхности псевдотуберкулезного микроба изучали с использованием электрооптического [2], литического методов [4], путем анализа жирных кислот (ЖК) методом газожидкостной хроматографии [3].

\section{Результаты и обсуждение}

Лаг-фаза обычно характеризует адаптивные возможности микроорганизмов к изменению условий окружающей среды. Продолжительность лаг-фазы глубинного культивирования увеличивается при снижении температуры выращивания и при температуре $37^{\circ} \mathrm{C}$ была приблизительно в 2 раза короче по сравнению с температурой $10^{\circ} \mathrm{C}$ (табл. 1). Культура, выращенная при температуре $27^{\circ} \mathrm{C}$, по продолжительности лаг-фазы занимала промежуточное положение. Вероятно, указанное различие обусловлено возрастанием интенсивности процессов клеточного метаболизма при повышении температуры культивирования, что, в целом, находит подтверждение при изучении дыхательной активности культур по показателю КСД гл.25. Так, $10{ }^{\circ} \mathrm{C}$-ные культуры, в отличие от 27 - и $37^{\circ} \mathrm{C}$-ных, начинают активно утилизировать глюкозу лишь после 48 ч роста (табл. 2). Удельная эндогенная скорость потребления кислорода клетками также увеличивалась с повышением температуры выращивания: при температуре культивирования $10^{\circ} \mathrm{C}$ зна- чение показателя $\mathrm{V}_{\text {уд.эн. }}$ составило 62,$5 ; 27^{\circ} \mathrm{C}-112,0$ и $37^{\circ} \mathrm{C}-148,0$ нмоль $\mathrm{O}_{2} \cdot$ мллрд кл ${ }^{-1} \cdot$ мин $^{-1}$ (табл. 1 ).

Процент живых клеток сохраняется на достаточно высоком уровне на протяжении всего цикла культивирования $10{ }^{\circ} \mathrm{C}$-ной культуры (120 ч), в отличие от культур, выращенных при температуре $27^{\circ} \mathrm{C}$ и особенно при $37^{\circ} \mathrm{C}$. Наибольшее содержание ЛПС, в среднем, регистрировали в микробной суспензии, полученной в условиях глубинного выращенной при температуре $37^{\circ} \mathrm{C}$ (табл. 1).

Из представленных результатов (рис. 1) видно, что анизотропная поляризуемость (АП) всех изученных культур носит циклический характер. При этом кривая АП для клеток, полученных при температуре культивирования $10{ }^{\circ} \mathrm{C}$, менялась в широком диапазоне (от 145 до 512 отн. ед.); для клеток, выращенных при $37^{\circ} \mathrm{C}$, изменения носили менее выраженный (от 1 до 64 отн. ед) характер. АП клеток, выращенных при температуре $27^{\circ} \mathrm{C}$, занимает промежуточное положение. Объяснением появления циклического развития клеточной популяции является соответствие ее каждой волны (нарастание и спад сигнала) определенному этапу биохимических процессов и последовательной их смены. Минимум АП соответствует окончанию предыдущего процесса и старту следующего. Установлено, что циклический феномен АП определяется метаболическими механизмами, не связанными с делением клеток.

Линейное нарастание АП частично отражает повышение метаболической активности клеток, частично - увеличение их размеров. Учитывая это обстоятельство, можно сказать, что при пониженной 
Параметры дыхательной активности культур Y.pseudotuberculosis, выращенных в жидкой питательной среде при разных температурах $(\mathbf{X}, \mathbf{n = 3})$

\begin{tabular}{|c|c|c|c|c|c|c|c|c|c|c|}
\hline \multirow{2}{*}{$\begin{array}{c}\text { Температура } \\
\text { выращивания } \\
\text { культур, }{ }^{\circ} \mathrm{C}\end{array}$} & \multirow{2}{*}{$\begin{array}{c}\text { Показатель окислительного метаболизма культур } \\
\text { Y. pseudotuberculosis, единица измерения }\end{array}$} & \multicolumn{9}{|c|}{ Значение показателя на ... час культивирования } \\
\hline & & 0 & 12 & 18 & 24 & 36 & 48 & 72 & 96 & 120 \\
\hline \multirow[t]{2}{*}{10} & $\begin{array}{l}\text { Удельная эндогенная скорость дыхания по БК }\left(\mathrm{V}_{\text {уд. энд. }}\right) \text {, } \\
\text { нмоль } \mathrm{O}_{2} / \text { млрд кл.·мин }\end{array}$ & 62,5 & - & - & 8,0 & - & 5,2 & 3,7 & 4,2 & 3,0 \\
\hline & $\begin{array}{l}\text { Коэффициент стимуляции эндогенного дыхания глюкозой } \\
\left(\text { КСД }{ }_{\text {гл.25 }}\right) \text {, отн. ед. }\end{array}$ & 1,0 & - & - & 1,0 & - & 2,5 & 1,8 & 6,0 & 7,3 \\
\hline \multirow[t]{2}{*}{27} & $\begin{array}{l}\text { Удельная эндогенная скорость дыхания по БК }\left(\mathrm{V}_{\text {уд. энд. }}\right) \text {, } \\
\text { нмоль } \mathrm{O}_{2} / \text { млрд кл.•мин }\end{array}$ & 112,6 & 69,3 & 40,9 & 32,7 & 10,3 & - & - & - & - \\
\hline & $\begin{array}{l}\text { Коэффициент стимуляции эндогенного дыхания глюкозой } \\
\left(\text { КСД }{ }_{\text {гл.25 }}\right) \text {, отн. ед. }\end{array}$ & 4,5 & 3,2 & 4,6 & 5,2 & 4,2 & - & - & - & - \\
\hline \multirow[t]{2}{*}{37} & $\begin{array}{l}\text { Удельная эндогенная скорость дыхания по БК }\left(\mathrm{V}_{\text {уд. энд. }}\right) \text {, } \\
\text { нмоль } \mathrm{O}_{2} \text { /млрд кл.·мин }\end{array}$ & 148,0 & 67,9 & 21,9 & 3,6 & 7,5 & 2,7 & - & - & - \\
\hline & $\begin{array}{l}\text { Коэффициент стимуляции эндогенного дыхания глюкозой } \\
\left(\text { КС }{ }_{\text {r } 25}\right) \text {, отн. ед. }\end{array}$ & 2,0 & 1,0 & 1,0 & 2,0 & 3,0 & 1,0 & - & - & - \\
\hline
\end{tabular}

Примечание. «-» - исследование не проводилось.

температуре бактерии Y. pseudotuberculosis имели вытянутую (палочкообразную) форму, повышение температуры приводило к образованию коккообразных клеток. На завершающей стадии накопления биомассы размер клеток стремится к некоторой стационарной величине. Линейное увеличение АП прекращается. Биохимические процессы переходят в завершающую стадию, и их интенсивность ослабевает. Последняя волна изменения АП отражает завершающую стадию процесса биосинтеза. Из представленных кривых видно, что культуры, выращенные при температурах 10 и $27^{\circ} \mathrm{C}$, возможно, не достигли стационарной фазы.

Изменение АП на изучаемой частоте (500 кГц) обусловлено также и изменением электрических свойств внутриклеточного содержимого и зависит от барьерных свойств мембран. Так, клетки, полученные при низкой температуре, обладают высокой электропроводностью цитоплазмы и низкой электропроводностью клеточной стенки. Это обусловлено низкой текучестью цитозоля, в результате чего низкомолекулярные соединения не проходят через клеточную оболочку в межклеточное пространство, а высокомолекулярные образуют упорядоченные структуры, которые также поляризуются под действием

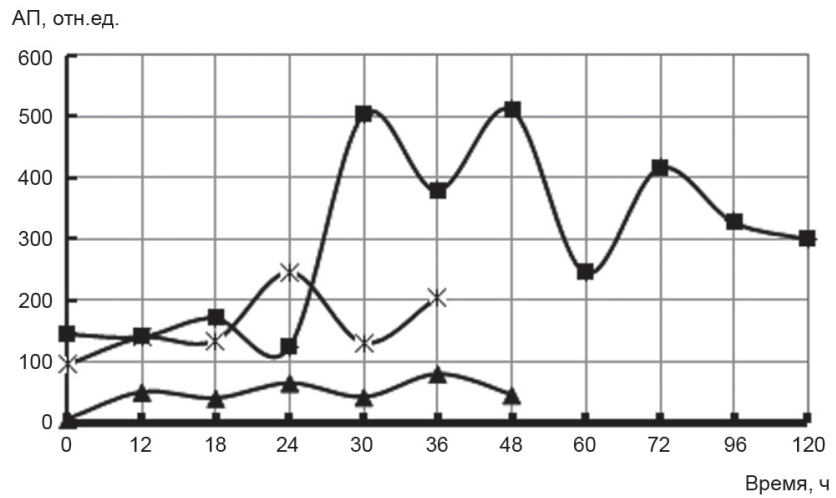

Рис. 1. Изменение анизотропии поляризуемости бактерий Y. pseudotuberculosis, выращенных

в жидкой питательной среде при разных температурах (частота электрического поля 500 мГц):

$$
\Delta-37^{\circ} \mathrm{C}, \times-27^{\circ} \mathrm{C}, \mathbf{-}-10^{\circ} \mathrm{C}
$$

электрического поля. С повышением температуры культивирования до $37^{\circ} \mathrm{C}$ текучесть компонентов клеток возрастает, упорядоченность структур бактериальной стенки ослабевает, в клетках начинают преобладать диффузионные процессы, и при возникновении повреждений в оболочке низкомолекулярные соединения выходят в межклеточное пространство. Это приводит к уменьшению АП за счет снижения диэлектрической проницаемости клеточной оболочки и электропроводности цитоплазмы.

Изучение динамики глубинного выращивания Y. pseudotuberculosis литическим методом показало, что середина логарифмической фазы для 27- и $37^{\circ} \mathrm{C}$-ных культур приходится на 12-16 ч культивирования, $10^{\circ} \mathrm{C}$-ных культур - на 78-80 ч (рис. 2). $27^{\circ} \mathrm{C}$-ная культура достигает зрелости к 24-36 ч выращивания. К 36 ч роста у $37^{\circ} \mathrm{C}$-ных культур регистрировалось снижение резистентности к додецилсульфат натрию (ДСН), что, вероятно, связано с токсическим действием на клеточную стенку продуктов обмена, накопившихся к этому времени в среде, и к 48 ч роста культура достигла фазы зрелости. $10{ }^{\circ} \mathrm{C}$-ная культура не достигает стационарной фазы развития даже через 120 ч выращивания.

Исследование ЖК-состава культур Y. pseudotuberculosis показало закономерное изменение его состава

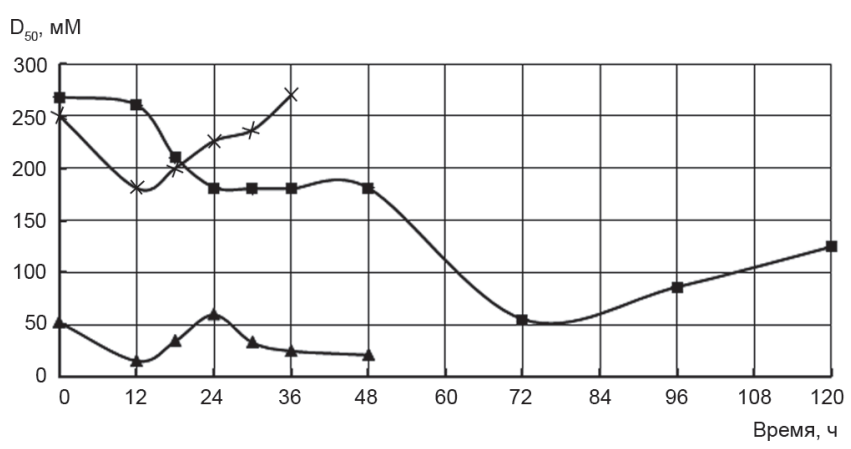

Рис. 2. Изменение показателя резистентности к ДСН $\left(\mathrm{D}_{50}\right)$ бактерий $Y$. pseudotuberculosis, выращенных в жидкой питательной среде при разных температурах: $\boldsymbol{\Delta}-37^{\circ} \mathrm{C}, \times-27^{\circ} \mathrm{C}, \mathbf{\square}-10^{\circ} \mathrm{C}$ 
Показатели жирно-кислотного состава клеток $Y$. pseudotuberculosis, выращенных в жидкой питательной среде при разных температурах $(\mathbf{X}, \mathbf{n}=3)$

\begin{tabular}{|c|c|c|c|c|c|c|c|c|c|}
\hline \multirow{2}{*}{$\begin{array}{c}\text { Температура } \\
\text { выращивания культур, } \\
{ }^{\circ} \mathrm{C}\end{array}$} & \multirow{2}{*}{$\begin{array}{c}\text { Показатель, } \\
\text { единица измерения }\end{array}$} & \multicolumn{8}{|c|}{ Величина показателя на ... час развития } \\
\hline & & 0 & 12 & 24 & 36 & 48 & 72 & 96 & 120 \\
\hline \multirow[t]{3}{*}{10} & I, усл.ед. & 2,32 & 1,10 & 2,04 & 2,18 & 2,00 & 1,72 & 1,54 & 1,50 \\
\hline & $\Sigma \nabla, \%$ & 5,80 & 1,60 & 1,40 & 1,40 & 5,70 & 4,70 & 10,50 & 9,80 \\
\hline & К ,отн.ед. & 1,72 & 1,12 & 2,04 & 2,19 & 1,71 & 1,63 & 1,35 & 1,20 \\
\hline \multirow[t]{2}{*}{27} & I, усл.ед. & 0,38 & 0,92 & 0,30 & 0,20 & - & - & - & - \\
\hline & $\mathrm{K}_{\mathrm{H}}$, отн.ед. & 0,20 & 0,81 & 0,34 & 0,31 & - & - & - & - \\
\hline \multirow[t]{3}{*}{37} & I, усл.ед. & 0,45 & 0,75 & 0,18 & - & 0,32 & - & - & - \\
\hline & $\Sigma \nabla, \%$ & 0,21 & 11,7 & 13,7 & - & 12,1 & - & - & - \\
\hline & $\mathrm{K}_{\mathrm{H}}$, отн.ед. & 0,16 & 0,22 & 0,16 & - & 0,21 & - & - & - \\
\hline
\end{tabular}

Примечания : $\mathrm{I}_{\mathrm{a}}$ - индекс активности жирно-кислотного пула, $\Sigma \nabla$ - сумма циклопропановых кислот, $\mathrm{K}_{\text {н }}-$ коэффициент ненасыщенности.

в процессе глубинного выращивания (табл. 3). После 12 ч роста для 27 - и $37^{\circ} \mathrm{C}$-ных и 36 ч для $10^{\circ} \mathrm{C}$-ных культур отмечается снижение индекса ЖК-пула $\left(\mathrm{I}_{\mathrm{a}}\right)$, уменьшение содержания ненасыщенных ЖК $\left(K_{\mathrm{H}}\right)$, синтез и накопление циклопропановых кислот $(\Sigma \nabla)$.

Как было установлено ранее, мембранные структуры клеток, находящихся в стационарной фазе развития, характеризуются низкими значениями показателей $\mathrm{I}_{\mathrm{a}}, \mathrm{K}_{\mathrm{H}}$ и высоким содержанием циклопропановых кислот $[1,3]$. Исходя из этого, а также результатов, представленных в табл. 3, можно полагать, что $10{ }^{\circ} \mathrm{C}$-ные культуры Y. pseudotuberculosis через 120 ч выращивания еще находятся в логарифмической стадии, 27- и $37^{\circ} \mathrm{C}$-ные культуры вышли на стационарную стадию развития к 36 и 48 ч культивирования соответственно. Тем не менее, пониженный индекс активности ЖК-пула и повышенное содержание циклопропановых жирных кислот у $27^{\circ} \mathrm{C}$-ных культур по сравнению с $37^{\circ} \mathrm{C}$-ными позволяет сделать заключение о том, что мембранные структуры клеток, развивавшихся при температуре $27^{\circ} \mathrm{C}$, более сформированы и характеризуются как «зрелые».

Таким образом, установлено, что периодическое культивирование псевдотуберкулезного микроба при температуре $37^{\circ} \mathrm{C}$ характеризуется быстрым развитием популяции и быстрым ее отмиранием. Для роста возбудителя в условиях низкой температуры характерны замедленная лаг-фаза, растянутая фаза экспоненциального роста, характеризующаяся высоким процентом живых микробов. По характеру роста $27^{\circ} \mathrm{C}$-ные культуры занимают промежуточное положение между 10 - и $37^{\circ} \mathrm{C}$-ными. Исследование бактерий, выращенных при температуре $10^{\circ} \mathrm{C}$, показало, что по показателям устойчивости к ДСН, эндогенной скорости дыхания, АП, ЖК-составу культура к завершению процесса культивирования (120 ч) не вышла на стационарную фазу роста.

\section{СПИСОК ЛИТЕРАТУРЫ}

1. Андреев А.В. Общие закономерности и специфические особенности биосинтеза и метаболизма у прокариот. В кн.: Клеточный уровень исследования. Доклады II Всесоюзной конференции. М.; 1982. С. 75-106.

2. Брезгунов В.Н., Швеи Н.В., Бунин В.Д., Волошин А.Г., Светогоров Д.Е., Щепкина А.Н., Определение электроопти- ческим методом числа неповрежденных бактериальных клеток после экстремальных воздействий. Микробиология. 1984; 54(4):616-20.

3. Еременко Ю.Д., Смирнов С.Г., Чернядьев А.В. Изменение жирнокислотного состава бактерий Y. pestis штамма EV в процессе глубинного выращивания. Биопрепараты. 2002; 1:21-3.

4. Иванов А.Ю., Фомченков В.М., Ажермачев А.К., Чугунов В.А., Мирошников А.И. Влияние поверхностно-активных веществ на электрические свойства бактериальных клеток. Микробиология. 1987; 58(6):969-75.

5. Лукоянова М.А., Тихонова Г.В. Организация дыхательной цепи и аккумуляция энергии у бактерий. Итоги науки и техники. Сер. Биол. химия. ВИНИТИ. 1982; 17:33-74.

6. Печенкин Д. В., Бывалов А.А., Маракулин И. В., Шабалин Б.А., Гаврилов K.E. Влияние капсулы Yersinia pestis на фагоцитарную активность перитонеальных макрофагов морской свинки. Пробл. особо опасных инф. 2005; 2(90):47-8.

K.E.Gavrilov, E.V.Serebryakova, T.Yu.Dunyasheva, N.N.Zaytseva, Yu.D.Eremenko, V.S.Lobastov, A.A.Byvalov, S.L.Kuznetsov, I.V.Borisevich

\section{Biological and Physical-Chemical Properties}

of Yersinia pseudotuberculosis Cultures in the Process of Submerged Cultivation at Various Temperatures

48 Central Research Institute of the Ministry of Defense of the Russian Federation"; The Institute of Physiology, Komi Science Center, the Ural Division of the Russian Academy of Sciences; Biological Defense Division of the Administration of the Commander of the Forces of Radiation, Chemical and Biological Defense of the Russian Federation Armed Forces

Biological and physical-chemical properties of the pseudotuberculosis agent cultures were shown to be diverse in the process of submerged cultivation at various temperatures. The microbe cultivation at the increased temperature $\left(37^{\circ} \mathrm{C}\right)$ was characterized by fast development and death of the population. Decelerated lag phase and extended exponential phase were observed under the conditions of cultivation at low temperature. The culture grown at $27^{\circ} \mathrm{C}$ was found to get an intermediate position between those grown at 10 and $37^{\circ} \mathrm{C}$.

Key words: Yersinia pseudotuberculosis, temperature of cultivation, lypopolysaccharide.

\section{Об авторах:}

Гаврилов К.Е., Серебрякова Е.В., Дунямева Т.Ю., Зайщева Н.Н., Еременко Ю.Д., Лобастов В.С., БорисевичИ.В. 48 Центральный научноисследовательский институт Министерства обороны РФ. Киров.

Бывалов А.А. Институт физиологии Коми научного центра Уральского отделения Российской академии наук. Киров.

Кузнеиов С.Л. Управление биологической защиты Управления начальника войск радиационной, химической и биологической защиты вооруженных сил РФ.

Authors:

Gavrilov K.E., Serebryakova E.V., Dunyasheva T.Yu., Zaytseva N.N., Eremenko Yu.D., Lobastov V.S., Borisevich I.V. 48 Central Research Institute of the Ministry of Defense of the Russian Federation. Kirov.

Byvalov A.A. The Institute of Physiology, Komi Science Center, the Ural Division of the Russian Academy of Sciences. Kirov.

Kuznetsov S.L. Biological Defense Division of the Administration of the Commander of the Forces of Radiation, Chemical and Biological Defense of the Russian Federation Armed Forces.

Поступила 05.11.09. 